\title{
ANALISIS DOSIS RADIASI ALAM RADON DAN SINAR GAMMA DI RUMAH PENDUDUK KALIMANTAN BARAT
}

\section{ANALYSIS OF NATURAL RADIATION DOSE OF RADON AND GAMMA RAYS IN RESIDENT HOUSES OF WEST KALIMANTAN}

\author{
Wahyudi1, Kusdiana1, Muji Wiyono¹, Dadong Iskandar² \\ ${ }^{1}$ Pusat Teknologi Keselamatan dan Metrologi Radiasi - BATAN \\ 2Pusat Teknologi Limbah Radioatif - BATAN \\ J. Lebak Bulus Raya No.49, Jakarta 12440 \\ E-mail : wah_yudi@batan.go.id
}

Diterima 13 Desember 2018, diterima dalam bentuk perbaikan 23 April 2019, disetujui 18 Juli 2019

\begin{abstract}
ABSTRAK
ANALISIS DOSIS RADIASI ALAM RADON DAN SINAR GAMMA DI RUMAH PENDUDUK KALIMANTAN BARAT. Telah dilakukan analisis dosis radiasi alam yang berasal dari radiasi radon dan radiasi gamma di rumah penduduk Kalimantan Barat. Data dosis radiasi ini akan berguna bagi pengambilan keputusan dalam mengidentifikasi status kesehatan yang terkait dengan radiasi pengion di Indonesia. Dosis radon diukur menggunakan metode pasif dengan detektor jejak nuklir CR-39 yang dipasang di rumah penduduk selama 34 bulan, sedangkan dosis radiasi gamma diukur secara langsung menggunakan surveimeter model Ludlum19. Dari hasil analisis detektor jejak nuklir CR-39 diperoleh konsentrasi aktivitas radon di dalam rumah

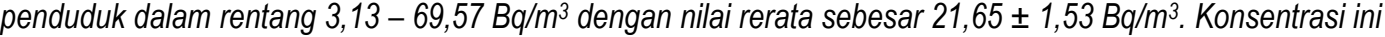
masih di bawah tingkat referensi radon yang ditetapkan oleh UNSCEAR sebesar $300 \mathrm{~Bq} / \mathrm{m}^{3}$. Sedangkan dari pengukuran konsentrasi Ra-226 dalam bahan bangunan diperoleh hasil dalam rentang 4,75-15,75 Bq/kg. Hasil analisis dosis yang berasal dari radon di rumah penduduk diperoleh nilai dalam rumah dalam rentang nilai 0,08 - 1,11 mSv/tahun dengan rerata sebesar 0,38 $\pm 0,03 \mathrm{mSv} /$ tahun. Dari hasil pengukuran dosis radiasi gamma diperoleh nilai 0,15 - 0,23 mSv/tahun sehingga dosis radiasi alam yang diterima penduduk di Kalimantan Barat sebesar 0,55 - 1,32 mSv/tahun dengan nilai rerata sebesar 0,69 \pm 0,20 mSv/tahun. Dapat disimpulkan bahwa dosis radiasi radon di dalam rumah Kalimantan Barat masih di bawah dosis rata-rata di dunia yang nilainya sebesar $2.4 \mathrm{mSv} / \mathrm{tahun}$.
\end{abstract}

Kata kunci: dosis radiasi alam, konsentrasi radon, detektor CR-39, rumah penduduk, Kalimantan Barat.

\begin{abstract}
ANALYSIS OF NATURAL RADIATION DOSES OF RADON AND GAMMA RAYS IN RESIDENT HOUSES OF WEST KALIMANTAN. Analysis of natural radiation doses of radon radiation and gamma radiation have been carried out in resident houses of West Kalimantan. These radiation doses data will be useful for decision makers in identifiying health status associated with ionizing in Indonesia. The radon doses were measured using a passive method with CR-39 nuclear track detectors installed in resident houses for 3-4 months, while the gamma radiation doses were measured directly using gamma surveimeter Ludlum-19 model. From the obtained results of the analysis of the CR-39. the radon concentration in resident houses were in the range of $3.13-69.57 \mathrm{~Bq} / \mathrm{m}^{3}$ with an average value of $21.65 \pm 1.53 \mathrm{~Bq} / \mathrm{m}^{3}$. These concentrations are below the radon reference level set by UNSCEAR of $300 \mathrm{~Bq} / \mathrm{m}^{3}$. The obtained results of measurement of Ra-226 concentration in building materials were in the range of $4.75-15.75 \mathrm{~Bq} / \mathrm{kg}$. The obtained results of the analysis of doses derived from radon in the houses were in the value range of $0.08-1.11 \mathrm{mSv} / \mathrm{year}$ with an average of $0.38 \pm 0.03 \mathrm{mSv} /$ year. Whereas the obtained gamma radiation doses measured directly using the surveimeter were $0.15-0.23 \mathrm{mSv} / \mathrm{year}$. So that the range of doses of natural radiation received by residents in West Kalimantan were $0.55-1.32 \mathrm{mSv} / \mathrm{year}$ with an average of $0.69 \pm 0.20 \mathrm{mSv} / \mathrm{year}$. It can be concluded that the radiation doses originating from radon exposure in houses of West Kalimantan are still below the world average dose of $2.4 \mathrm{mSv} / \mathrm{year}$
\end{abstract}

Keywords: natural radiation dose, radon concentration, CR-39 detector, residents houses, West Kalimantan. 
Jurnal Iptek Nuklir Ganendra

Ganendra Journal of Nuclear Science and Technology

Vol. 22 No. 2, Juli 2019: 63-72

\section{PENDAHULUAN}

Denelitian tentang pengukuran radiasi dan radioaktivitas lingkungan telah banyak dilakukan sebelumnya [1-3], namun penelitian tersebut belum mencakup paparan radiasi alamiah yang berasal dari radon dan thoron. Berdasarkan Laporan UNSCEA R (United Nations Scientific Committee on the Effects of Atomic Radiation) paparan radiasi radon di rumah merupakan penyumbang terbesar bagi paparan radiasi alam yang mencapai $50 \%$ [4]. Sedangkan paparan radiasi alam merupakan penyumbang terbesar dosis radiasi alam yaitu mencapai $85 \%$ dari seluruh dosis paparan radiasi yang diterima penduduk dunia. Dalam upaya mengelaborasi sumber radiasi alam di Indonesia sehingga dapat dikarakterisasi maka perlu dilakukan pengukuran konsentrasi radonthoron di rumah penduduk.

Radon (Rn-222) dan thoron (Rn-220) adalah zat radioaktif alamiah berbentuk gas yang dapat menimbulkan masalah radiologik yang cukup signifikan [5]. Radon dan anak luruhnya seperti Po-218, Pb-214, Bi214 atau Po-214 merupakan radionuklida berumur pendek pemancar alfa dan dapat menempel pada partikel halus di udara yang jika terhirup akan memberikan pajanan radiasi pada jaringan paru-paru sehingga dapat menaikkan risiko kanker. Isotop radon yang lain yaitu radon-220 (thoron) juga memiliki sifat yang sama tetapi dengan derajat dosis radiasi di paru-paru yang lebih kecil.

Provinsi Kalimantan Barat secara geografis terletak pada $2^{\circ} 08^{\prime}-3^{\circ} 05^{\prime}$ Lintang Selatan dan $108^{\circ} 0^{\prime}-$ $114^{\circ} 10^{\prime}$ Bujur Timur dengan garis khatulistiwa atau titik $0^{\circ} 00^{\prime}$ terletak di Kota Pontianak. Dilihat dari tekstur tanahnya maka, sebagian besar daerah Kalimantan Barat terdiri atas jenis tanah podsolet merah kuning, orgosol, gley dan humus dan aluvial. Secara umum struktur tanah di Kalimantan Barat tersusun oleh batuan tua berumur Trias ( \pm 204 juta tahun) berupa batu pasir berlapis, andesit, granit yang ditutupi di atasnya oleh batuan sedimen dan aluvium berumur Kuarter (<1,6 juta tahun). Struktur tanah di daerah pantai tersusun oleh batuan aluvium, batuan sedimen dan untuk beberapa tempat berupa batuan terobosan meliputi granit, granodiorit dan dasit [6]. Jenis-jenis pertambangan yang banyak diusahakan di wilayah Kalimantan Barat adalah bouksit, emas dan batubara, serta pertambangan batuan uranium yang dikelola BATAN yang berada di Kalan, Kec. Nangapinoh, Kab. Melawi [6].

Adanya potensi bahaya dari dosis radiasi radon menyebabkan dimasukkannya pemetaan tingkat konsentrasi radon di wilayah Kalimantan Barat sebagai bagian dari rencana pemetaan radon thoron di seluruh wilayah Indonesia. Pemetaan konsentrasi radon di wilayah Kalimantan Barat belum pernah dilakukan sehingga hasil pemetaan akan dapat menjadi bagian dari data konsentrasi radon di seluruh wilayah Indonesia. Manfaat lain dari pemetaan ini adalah sebagai bagian dari kontribusi Indonesia di dunia internasional melalui UNSCEAR, IAEA dan WHO mengenai data konsentrasi radon di rumah penduduk. Bagi pemerintah daerah, data ini dapat menjadi pertimbangan dalam perencanaan pengembangan dan pembangunan daerah yang terkait dengan masalah radiasi. Pada Gambar 1 disajikan mekanisme pergerakan gas radon di dalam sebuah rumah menurut UNSCEAR [5]. Terlihat di dalam Gambar 1 bahwa radon yang merupakan gas radioaktif muncul dari bebatuan dan tanah serta menyebar ke udara dalam rumah melalui retakan di lantai/tanah atau masuk melalui jendela. Sumber gas radon dalam rumah tersebut berasal dari infiltrasi tanah, air tanah, serta bahan bangunan dengan radioaktivitas yang tinggi.

\section{METODOLOGI}

\section{Peralatan dan Bahan}

Peralatan yang digunakan adalah alat penentu lokasi (GPS), surveimeter model Ludlum-19, alat sampling tanah dan bahan bangunan, alat monitor radon pasif dengan detektor jejak nuklir CR-39, tangga aluminium, palu, staining jar, oven, ultrasonic vibrator, desikator elektrik, mikroskup. Sedangkan bahan yang digunakan adalah tali senar, paku kecil, $\mathrm{NaOH} 6,25 \mathrm{~N}$, aceton, gelas objek dan wadahnya. Sedangkan sebagai pendukung adalah leaflet dan peta wilayah Kalimantan Barat dengan grid $60 \mathrm{~km} \times 60 \mathrm{~km}$ sebagaimana diperlihatkan pada Gambar 2. Untuk analisis radioaktivitas dalam sampel bahan bangunan digunakan peralatan berupa spektrometer gamma dengan detektor HPGe model GEM F5930 buatan Ortec-USA dengan efisiensi relatif sebesar $21 \%$ pada energi $1332,5 \mathrm{keV}$, beaker Marinelli volume satu liter dan lem araldhit.

Penentuan titik lokasi sampling dibuat dalam bentuk grid. Hal ini dimaksudkan agar data yang diperoleh dapat tersebar secara merata. Pembuatan grid dilakukan dengan menggunakan software Mapsource. 


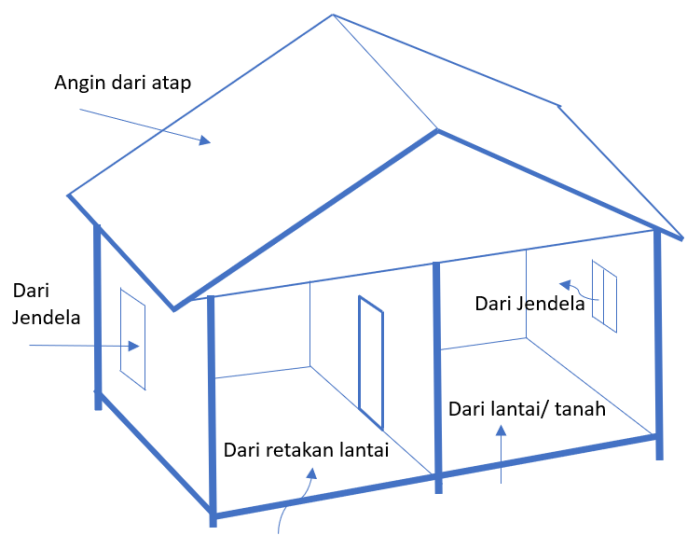

Gambar 1. Mekanisme pergerakan radon di dalam ruangan [5].

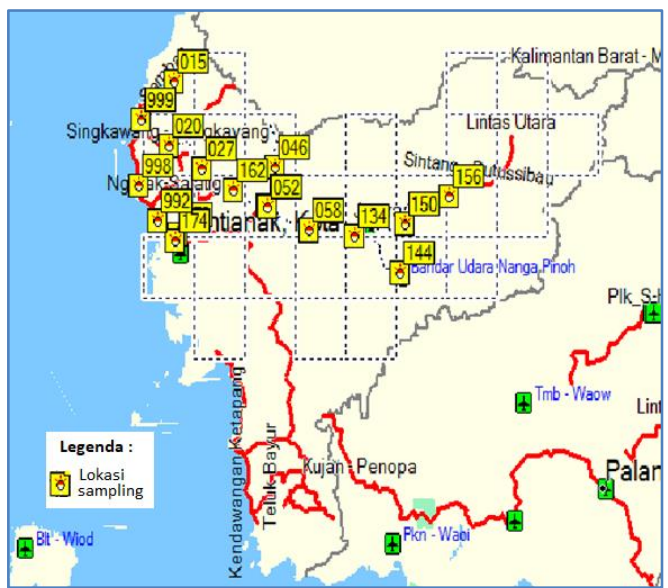

Gambar 2. Peta Kalimantan Barat dengan grid 60km x 60km.
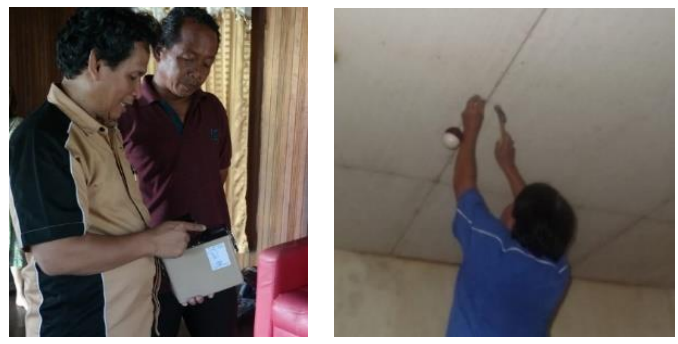

Gambar 3. Pengukuran laju paparan dosis radiasi gamma (kiri) dan pemasangan alat monitor radon pasif di dalam rumah penduduk (kanan)

\section{Prosedur Kerja}

Tracking dilakukan dengan menggunakan GPS pada grid yang akan dituju dan terdapat rumah penduduk atau perkampungan setelah didahului dengan koordinasi dengan kepala desa untuk dilakukan sampling. Sampling dilakukan terhadap 6-10 rumah dengan setiap rumah masing-masing diukur laju paparan dosis radiasi gamma di dalam rumah dan dipasang alat monitor radon pasif dengan detektor CR-39. Detektor tersebut diletakkan di dalam suatu wadah bola plastik yang dirancang untuk mendeteksi konsentrasi radon di udara. Titik lokasi detektor ditandai dengan posisi garis bujur dan lintang mengugunakan GPS. Alat monitor radon pasif dipasang dengan cara digantungkan pada plafon rumah selama 3 sampai 4 bulan yaitu pada bulan Maret sampai Juni 2016. Pemantauan radon dengan metode pasif selama 3-4 bulan sudah mewakili rentang satu tahun dikarenakan pada saat musim penghujan juga terdapat kondisi cuaca yang panas atau kering, sehingga kondisi ini sebagai bagian dari penelitian awal telah terwakili. Proses pemasangan alat monitor radon pasif dan 
pengukuran laju dosis di dalam rumah yang dilakukan oleh personel penelitian ditampilkan pada Gambar 3. Di setiap grid dilakukan juga sampling terhadap bahan bangunan utama rumah penduduk. Pada umumnya rumah di Kalimantan Barat menggunakan bahan bangunan berupa batako semen-pasir atau bata merah, sehingga kedua jenis bahan bangunan ini yang dipilih untuk dijadikan sampel.

Di seluruh wilayah Kalimantan Barat dapat dipasang telah sebanyak 110 buah detektor jejak nuklir di 16 lokasi dalam grid. Dari 110 buah detektor yang dipasang tersebut setelah 3 bulan berhasil diambil kembali sebanyak 107 buah atau $97,27 \%$, sedangkan sisanya dalam kondisi rusak.

Sampel bahan bangunan yang berhasil dikumpulkan dipreparasi sesuai dengan Standar Operasional Prosedur yang digunakan di Laboratorium Keselamatan Lingkungan PTKMR BATAN. Untuk analisis konsentrasi radionuklida Ra-226, Th-232 dan K-40 dalam sampel bahan bangunan digunakan spektrometer gamma yang dilengkapi dengan detektor Germanium kemurnian tinggi dengan batas terendah yang dapat dideteksi (MDC) untuk Ra-226, Th-232 dan K-40 sebesar 0,15 Bq/kg; 0,14 Bq/kg dan 1,02 Bq/kg untuk lama pencacahan sampel 17 jam.

Proses etsa monitor radon pasif dilakukan dengan merendam detektor CR-39 di dalam staining jar menggunakan larutan $\mathrm{NaOH} 6,25 \mathrm{~N}$, kemudian memanaskannya di dalam oven pada suhu $70 \pm 2^{\circ} \mathrm{C}$ selama 7 jam (Gambar 4). Setelah itu detektor CR-39 dicuci 3-4 kali menggunakan aquadest untuk membersihkan larutan $\mathrm{NaOH}$ kemudian dicuci kembali dengan pencuci ultrasonic vibrator selama 5 menit. Setelah selesai pencucian detektor CR-39 dikeringkan pada suhu kamar di dalam desikator elektrik selama 2 hari. Kemudian CR-39 dipindahkan ke atas gelas obyek dengan permukaan yang terpapar radiasi menghadap ke atas.

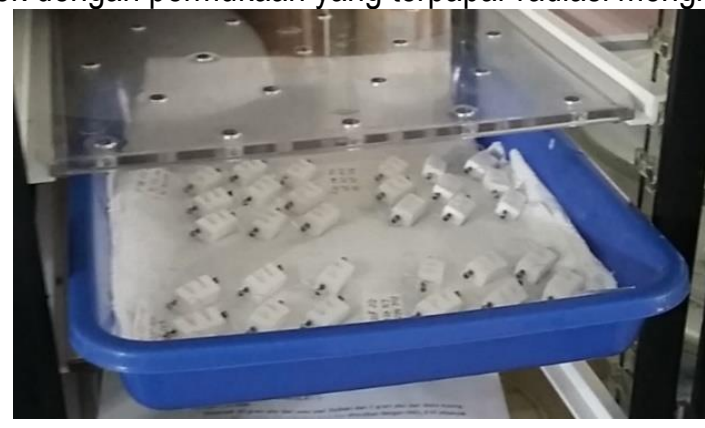

Gambar 4. Detektor CR-39 dikeringkan dalam desikator elektrik.

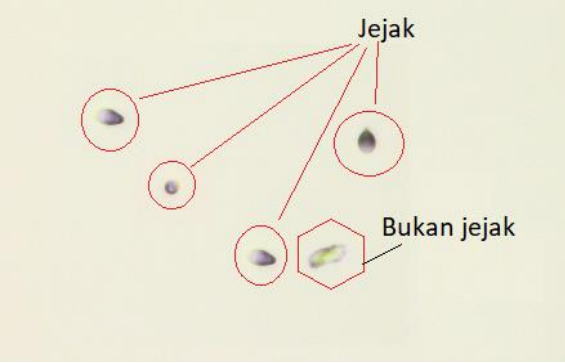

Gambar 5. Hasil pembacaan jejak radon menggunakan mikroskop dengan perbesaran 400 kali.

Jejak yang ada pada detektor CR-39 dibaca menggunakan mikroskop sebanyak 25 kali jumlah pandang pada perbesaran 400 kali pada luasan $5.0625 \mathrm{~mm}^{2}$. Berdasarkan jumlah jejak yang terbaca maka dapat ditentukan nilai konsentrasi radon yang berada di dalam rumah. Jejak radon mempunyai karakteristik yang unik yaitu berbentuk seperti tetesan air yang mulus pada lingkaran luarnya. Jejak radon pada detektor CR-39 akan terlihat berupa lingkaran hitam jika partikel alpha mengenai CR-39 secara tegak lurus dan akan terlihat seperti tetes air jika partikel alpha mengenai CR-39 secara menyudut. Hasil pembacaan jejak detektor CR-39 dapat dilihat pada Gambar 5, jejak di dalam lingkaran merah merupakan jejak partikel alpha dari radon baik yang datang dengan arah menyudut maupun dengan arah tegak lurus dengan membentuk bulatan hitam, sedangkan jejak di dalam kotak segi enam merupakan pengotor atau bukan jejak partikelalpha. 
Pada metode pasif ini konsentrasi radon berbanding lurus dengan jumlah jejak di dalam detektor CR-39, dan dapat dihitung menggunakan Persamaan 1 berikut [7]:

$C_{R n}=\frac{N_{T}-N_{B}}{E \times T}$

dengan $\mathrm{C}_{\mathrm{Rn}}$ adalah konsentrasi radon, $\mathrm{N}_{T}$ adalah jumlah jejak detektor dan $\mathrm{N}_{\mathrm{B}}$ adalah jejak latar, Eefisiensi detektor [(jejak/ $\left.5.0625 \mathrm{~mm}^{2}\right) / \mathrm{Bq} / \mathrm{m}^{3}$. hari)] atau faktor kalibrasi radon sebesar 0.00241 dan $\mathrm{T}$ adalah waktu pemaparan atau pemasangan (hari). Angka 5.0625 adalah luas area untuk 25 kali jumlah pandang pada pembacaan jejak di bawah mikroskop pada perbesaran 400 kali. Dari hasil pengukuran konsentrasi radon di dalam rumah penduduk, maka dapat diperkirakan dosis efektif yang diterima penduduk menggunakan persamaan sebagai berikut [7] :

$D_{R n}=F_{k R n} \cdot F_{R n} . T . C_{R n}(m S v / t a h u n)$

dengan:

$\mathrm{F}_{\mathrm{kRn}}=$ faktor kesetimbangan radon dengan anak luruhnya $(0,4)$

$\mathrm{F}_{\mathrm{Rn}} \quad=$ faktor konversi dosis radon $\left(9 \mathrm{nSv} / \mathrm{Bq} . \mathrm{jam} / \mathrm{m}^{3}\right)$

$\mathrm{T}$ = lama tinggal di dalam rumah (jam/tahun)

$\mathrm{C}_{\mathrm{Rn}}=$ konsentrasi gas radon di dalam rumah $\left(\mathrm{Bq} / \mathrm{m}^{3}\right)$

$D_{R n} \quad=$ Dosis efektif akibat menghirup radon dan luruhannya yang berumur pendek (mSv/tahun).

Berdasarkan data konsentrasi radon dan data GPS dapat dibuat peta kontur konsentrasi radon menggunakan software Surfer dan Maplnfo. Agar perbedaan tingkat konsentrasi radon di dalam rumah dapat dilihat dengan mudah maka dibuat degradasi warna pada peta digital. Semakin gelap warna pada peta menunjukkan tingkat konsentrasi radon yang makin tinggi dan sebaliknya.

\section{HASIL DAN PEMBAHASAN}

Pengukuran dosis radiasi gamma di dalam rumah penduduk dilakukan dengan menggunakan surveimeter model Ludlum-19. Surveimeter ini mempunyai kemampuan ukur laju dosis terendah dalam orde nSv/jam. Dosis yang diterima penduduk dari paparan radiasi gamma dihitung dengan asumsi mereka rata-rata berada di dalam rumah selama 14 jam per hari yaitu dari jam 17.00 sampai dengan jam 07.00 pagi. Hasil analisis dosis efektif radiasi gamma yang diterima penduduk selama di dalam rumah dalam satu tahun secara lengkap disajikan pada Tabel 1.

Tabel 1. Lokasi pengambilan data dan dosis tahunan dari radiasi gamma di wilayah Kalimantan Barat yang diukur menggunakan surveimeter model Ludlum-19.

\begin{tabular}{|c|c|c|c|c|}
\hline \multirow{2}{*}{ No. } & \multirow{2}{*}{ Lokasi Sampling } & \multicolumn{2}{|c|}{ Koordinat Lokasi } & \multirow{2}{*}{$\begin{array}{c}\text { Dosis } \\
\text { (mSv/tahun) }\end{array}$} \\
\hline & & Garis Lintang & Garis Bujur & \\
\hline 1 & Ds. Peniti Luar, Kec. Siantan, Kab. Mempawah & $0.12750 \mathrm{LU}$ & 109.15587 BT & $0,23 \pm 0,01$ \\
\hline 2 & Ds. Malikian, Kec. Mempawah Hilir, Kab. Mempawah & $0.44528 \mathrm{LU}$ & 108.94181 BT & $0,17 \pm 0,02$ \\
\hline 3 & Ds. Sungai Rusa, Kec.Selakanu, Kab. Sambas & 1.02617 LU & 108.98026 BT & $0,17 \pm 0,03$ \\
\hline 4 & Ds. Dalem Kaum, Kec. Sambas, Kab. Sambas & $1.36518 \mathrm{LU}$ & 109.31899 BT & $0,18 \pm 0,02$ \\
\hline 5 & Ds. Babane, Kec. Samalantan, Kab. Bengkayang & $0.79529 \mathrm{LU}$ & 109.26699 BT & $0,15 \pm 0,02$ \\
\hline 6 & Ds. Darit, Kec. Menyuke, Kab. Landak & 0.59396 LU & 109.62394 BT & $0,16 \pm 0,02$ \\
\hline 7 & Ds. Sebungkuh, Kec. Kembayan, Kab. Sanggau & 0.60166 LU & 110.39802 BT & $0,23 \pm 0,03$ \\
\hline 8 & Ds. Binjai, Kec. Tayan Hulu, Kab. Sanggau & $0.26632 \mathrm{LU}$ & 110.31059 BT & $0,21 \pm 0,02$ \\
\hline 9 & Ds. Sungai Kunyit, Kec. Sekadau Hilir, Kec. Sekadau & $0.04493 \mathrm{LU}$ & 110.76264 BT & $0,21 \pm 0,02$ \\
\hline 10 & Ds. Gernis Jaya, Kec. Sepauh, Kab. Sintang & $0.00090 \mathrm{LU}$ & 111.24978 BT & $0,18 \pm 0,02$ \\
\hline 11 & Ds. Tj. Niaga, Kec. Nanga Pinoh, Kab. Melawi & 0.33085 LS & 111.73616 BT & $0,18 \pm 0,02$ \\
\hline 12 & Ds. Gemba Raya, Kec. Kelam Permai, Kab. Sintang & 0.10457 LU & 111.78943 BT & $0,20 \pm 0,02$ \\
\hline 13 & Ds. Mubung, Kec. Hulu Gurung, Kab. Kapuas Hulu & $0.35533 \mathrm{LU}$ & $112.26338 \mathrm{BT}$ & $0,14 \pm 0,02$ \\
\hline 14 & Ds. Raja, Kec. Ngabang, Kab. Landak & $0.39961 \mathrm{LU}$ & 109.95533 BT & $0,21 \pm 0,02$ \\
\hline 15 & Gg. Sukur-5, Jl. Veteran, Kota Pontianak & 0.04223 LU & 109.34339 BT & $0,21 \pm 0,02$ \\
\hline 16 & Komp. Pemda. Kec. Siantan Hulu, Kota Pontianak & $0.00848 \mathrm{LU}$ & 109.36212 BT & $0,21 \pm 0,02$ \\
\hline
\end{tabular}


Jurnal Iptek Nuklir Ganendra

Ganendra Journal of Nuclear Science and Technology

Vol. 22 No. 2, Juli 2019: 63-72

Keterangan : Ds $=$ Desa, Kec. $=$ Kecamatan, Kab. $=$ Kabupaten

Dari Tabel 1 dapat dilihat bahwa dosis radiasi gamma di dalam rumah penduduk dalam rentang dari $(0,14$ $\pm 0,02) \mathrm{mSv} /$ tahun sampai dengan $(0,23 \pm 0,03) \mathrm{mSv} /$ tahun. Nilai terendah terdapat di Desa Mubung, Kecamatan Hulu Gurung, Kabupaten Kapuas Hulu. Hal ini kemungkinan karena kondisi tempat penelitian berupa tanah rawa dengan sebagian besar berupa rumah panggung, sehingga posisi pengukuran berjarak lebih tinggi dari tanah. Sedangkan di Desa Sebungkuh, Kecamatan Kembayan, Kabupaten Sanggau dan Desa Peniti Luar, Kecamatan Siantan, Kabupaten Mempawah diperoleh dosis yang relatif lebih tinggi karena pada umumnya posisi bangunan rumah berada langsung di atas tanah sehingga jarak pengukuran relatif dekat dengan tanah. Secara keseluruhan nilai dosis radiasi gamma di wilayah Kalimantan Barat dipengaruhi faktor geologi dan sistem ventilasi rumah. Secara umum penduduk Kalimantan Barat menerima dosis radiasi eksterna dari paparan radiasi gamma dan dosis interna dari inhalasi gas radon.

Tabel 2. Konsentrasi radon di dalam rumah penduduk di Kalimantan Barat

\begin{tabular}{|c|c|c|c|}
\hline No. & Lokasi & Rentang Nilai $\left(\mathrm{Bq} / \mathrm{m}^{3}\right)$ & Rerata $\left(\mathrm{Bq} / \mathrm{m}^{3}\right)$ \\
\hline 1. & \multirow{2}{*}{$\begin{array}{l}\text { Ds. Peniti Luar, Kec. Siantan, Kab. Mempawah } \\
\text { Ds. Malikian, Kec. Mempawah Hilir, Kab. } \\
\text { Mempawah }\end{array}$} & $3,16 \pm 0,22$ sd. $22,14 \pm 1,57$ & $16,44 \pm 1,16$ \\
\hline 2. & & $6,32 \pm 0,45$ sd. $18,97 \pm 1,34$ & $16,47 \pm 1,16$ \\
\hline 3. & Ds. Sungai Rusa, Kec.Selakanu, Kab. Sambas & 0,89 sd. $18,80 \pm 1,33$ & 1,06 \\
\hline 4. & Ds. Dalem Kaum, Kec. Sambas, Kab. Sambas & $6,32 \pm 0,45$ sd. $25,30 \pm 1,79$ & 1,03 \\
\hline 5. & Ds. Babane, Kec. Samalantan, Kab. Bengkayang & $3,16 \pm 0,22$ sd. $28,20 \pm 1,99$ & $16,44 \pm 1,16$ \\
\hline 6. & Ds. Darit, Kec. Menyuke, Kab. Landak & $9,40 \pm 0,66$ sd. $28,80 \pm 1,33$ & $15,48 \pm 1,09$ \\
\hline 7. & Ds. Sebungkuh, Kec. Kembayan, Kab. Sanggau & $3,13 \pm 0,22$ sd. $34,46 \pm 2,44$ & $23,55 \pm 1,67$ \\
\hline 8. & Ds. Binjai, Kec. Tayan Hulu, Kab. Sanggau & $6,27 \pm 0,44$ sd. $21,93 \pm 1,55$ & $17,75 \pm 1,28$ \\
\hline 9. & $\begin{array}{l}\text { Ds. Sungai Kunyit, Kec. Sekadau Hilir, Kec. } \\
\text { Sekadau }\end{array}$ & 92 & 16 \\
\hline 10. & Ds. Gernis Jaya, Kec. Sepauh, Kab. Sintang & $6,27 \pm 0,4$ & $29,33 \pm 2,07$ \\
\hline 11. & Ds. Tj. Niaga, Kec. Nanga Pinoh, Kab. Melawi & $3,13 \pm 0,22$ sd. $47,00 \pm 3,32$ & $16,44 \pm 1,16$ \\
\hline 12. & Ds. Gemba Raya, Kec. Kelam Permai, Kab. Sintang & $6,27 \pm 0,44$ sd. $18,80 \pm 1,33$ & $15,43 \pm 1,09$ \\
\hline 13. & Ds. Mubung, Kec. Hulu Gurung, Kab. Kapuas Hulu & $6,27 \pm 0,44$ sd. $28,20 \pm 1,99$ & $24,89 \pm 1,76$ \\
\hline 14. & Ds. Raja, Kec. Ngabang, Kab. Landak & $3,16 \pm 0,22$ sd. $22,14 \pm 1,57$ & $13,81 \pm 0,98$ \\
\hline 15. & Gg. Sukur-5, Jl. Veteran, Kota Pontianak & $3,38 \pm 0,24$ sd. $23,67 \pm 1,67$ & $15,78 \pm 1,12$ \\
\hline 16. & Komp. Pemda. Kec. Siantan Hulu, Kota Pontianak & $6,76 \pm 0,48$ sd. $23,67 \pm 1,67$ & $15,64 \pm 1,11$ \\
\hline & Kalimantan Barat & $3,13 \pm 0,22$ sd. $69,57 \pm 4,92$ & $21,65 \pm 1,53$ \\
\hline
\end{tabular}

Konsentrasi radon di rumah penduduk dihitung menggunakan Persamaan 1. Hasil analisis konsentrasi radon di dalam rumah penduduk di Kalimantan Barat diperoleh rentang nilai $(3,13 \pm 0,22) \mathrm{Bq} / \mathrm{m}^{3}$ sampai dengan $(69,57 \pm 4,92) \mathrm{Bq} / \mathrm{m}^{3}$ dengan nilai rerata sebesar $(21,65 \pm 1,53) \mathrm{Bq} / \mathrm{m}^{3}$ dan secara lengkap disajikan pada Tabel 2. Besarnya konsentrasi radon di rumah penduduk pada umumnya dipengaruhi oleh kondisi geologi pada daerah pengukuran, tipe rumah, sistem pertukaran udara di dalam rumah, dan jenis bahan bangunan yang digunakan untuk bangunan rumah. Rumah sederhana yang terbuat dari bahan kayu tanpa plafon mempunyai sistem pertukaran udara yang paling baik sehingga konsentrasi radonnya rendah. Sedangkan untuk rumah permanen umumnya dibuat dari batako semen-pasir, serta sebagian menggunakan plafon sehingga mempunyai sistem pertukaran udara yang kurang baik. Jenis plafon yang terbuat dari gypsum dapat meningkatkan konsentrasi radon di dalam rumah [8]. Rumah jenis permanen ini mempunyai konsentrasi radon yang relatif lebih tinggi dibandingkan dengan rumah sederhana.

Konsentrasi radon di rumah penduduk dihitung menggunakan Persamaan 1. Hasil analisis konsentrasi radon di dalam rumah penduduk di Kalimantan Barat diperoleh rentang nilai $(3,13 \pm 0,22) \mathrm{Bq} / \mathrm{m}^{3}$ sampai dengan $(69,57 \pm 4,92) \mathrm{Bq} / \mathrm{m}^{3}$ dengan nilai rerata sebesar $(21,65 \pm 1,53) \mathrm{Bq} / \mathrm{m}^{3}$ dan secara lengkap disajikan pada Tabel 2. Besarnya konsentrasi radon di rumah penduduk pada umumnya dipengaruhi oleh kondisi geologi pada daerah pengukuran, tipe rumah, sistem pertukaran udara di dalam rumah, dan jenis bahan bangunan yang digunakan 
untuk bangunan rumah. Rumah sederhana yang terbuat dari bahan kayu tanpa plafon mempunyai sistem pertukaran udara yang paling baik sehingga konsentrasi radonnya rendah. Sedangkan untuk rumah permanen umumnya dibuat dari batako semen-pasir, serta sebagian menggunakan plafon sehingga mempunyai sistem pertukaran udara yang kurang baik. Jenis plafon yang terbuat dari juga gypsum dapat meningkatkan konsentrasi radon di dalam rumah [8]. Rumah jenis permanen ini mempunyai konsentrasi radon yang relatif lebih tinggi dibandingkan dengan rumah sederhana.

Untuk memudahkan dalam melihat konsentrasi radon di dalam rumah penduduk di Kalimantan Barat maka dari data pada Tabel 2 dibuat peta yang disajikan dalam bentuk peta kontur. Pada Gambar 6 terlihat bahwa konsentrasi radon pada umumnya di bawah $50 \mathrm{~Bq} / \mathrm{m}^{3}$ kecuali di wilayah Desa Sungai Kunyit, Kecamatan Sekadau Hilir, Kabupaten Sekadau terdapat satu rumah dengan konsentrasi tertinggi yaitu $(69,57 \pm 4,92) \mathrm{Bq} / \mathrm{m}^{3}$. Kemungkinan hal ini disebabkan oleh sistem ventilasi rumah yang kurang baik karena kondisi rumah yang sering tertutup yang bertujuan untuk mengurangi debu yang masuk ke dalam rumah. Konsentrasi Ra-226 dalam sampel bahan bangunan sebagai salah satu penyumbang konsentrasi radon di lokasi tersebut relatif lebih tinggi dibanding daerah lainnya, walaupun masih di bawah tingkat maksimal radon yang ditetapkan oleh Komisi Internasional untuk Proteksi Radiasi (International Commission on Radiological Protection, ICRP) dan Badan Tenaga Atom Internasional (International Atomic Energy Agency, IAEA) yaitu sebesar $300 \mathrm{~Bq} / \mathrm{m}^{3}$ [5].

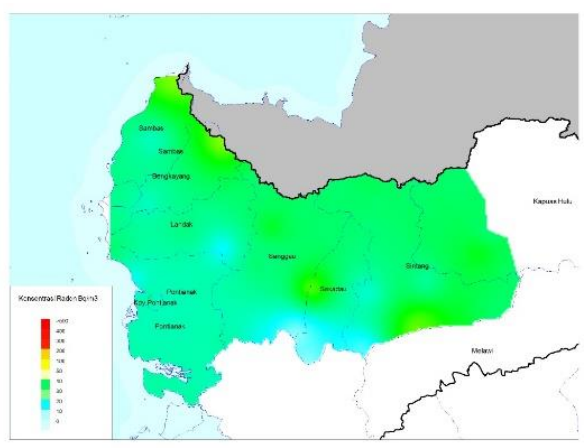

Gambar 6. Peta konsentrasi radon wilayah Kalimantan Barat

Tabel 3. Dosis radiasi alam dari gas radon di dalam rumah penduduk di Kalimantan Barat

\begin{tabular}{lll}
\hline No. & Lokasi & Dosis radon (mSv/tahun) \\
\hline 1. & Ds. Peniti Luar, Kec. Siantan, Kab. Mempawah & $0.43 \pm 0.03$ \\
2. & Ds. Malikian, Kec. Mempawah Hilir, Kab. Mempawah & $0.41 \pm 0.03$ \\
3. & Ds. Sungai Rusa, Kec.Selakanu, Kab. Sambas & $0.38 \pm 0.03$ \\
4. & Ds. Dalem Kaum, Kec. Sambas, Kab. Sambas & $0.37 \pm 0.03$ \\
5. & Ds. Babane, Kec. Samalantan, Kab. Bengkayang & $0.50 \pm 0.03$ \\
6. & Ds. Darit, Kec. Menyuke, Kab. Landak & $0.38 \pm 0.03$ \\
7. & Ds. Sebungkuh, Kec. Kembayan, Kab. Sanggau & $0.59 \pm 0.04$ \\
8. & Ds. Binjai, Kec. Tayan Hulu, Kab. Sanggau & $0.45 \pm 0.03$ \\
9. & Ds. Sungai Kunyit, Kec. Sekadau Hilir, Kec. Sekadau & $1.11 \pm 0.08$ \\
10. & Ds. Gernis Jaya, Kec. Sepauh, Kab. Sintang & $0.52 \pm 0.04$ \\
11. & Ds. Tj. Niaga, Kec. Nanga Pinoh, Kab. Melawi & $0.71 \pm 0.05$ \\
12. & Ds. Gemba Raya, Kec. Kelam Permai, Kab. Sintang & $0.39 \pm 0.03$ \\
13. & Ds. Mubung, Kec. Hulu Gurung, Kab. Kapuas Hulu & $0.63 \pm 0.04$ \\
14. & Ds. Raja, Kec. Ngabang, Kab. Landak & $0.35 \pm 0.02$ \\
15. & Gg. Sukur-5, Jl. Veteran, Kota Pontianak & $0.40 \pm 0.03$ \\
16. & Komp. Pemda. Kec. Siantan Hulu, Kota Pontianak & $0.39 \pm 0.03$ \\
& Dosis rata-rata Kalimantan Barat & $0,69 \pm 0.20$ \\
\hline
\end{tabular}

Hasil tersebut hampir tidak berbeda jauh dengan hasil pengukuran radon di rumah penduduk di Kalimantan Timur $(5,94 \pm 0,42) \mathrm{Bq} / \mathrm{m}^{3}$ sampai dengan $(77,89 \pm 5,51) \mathrm{Bq} / \mathrm{m}^{3}[1]$ di Aceh $(3.32 \pm 0.23) \mathrm{Bq} / \mathrm{m}^{3} \mathrm{sd}$. $(68.30 \pm 4.83) \mathrm{Bq} / \mathrm{m}^{3}$ [2]. Hasil pengukuran yang dilakukan oleh peneliti lain diperoleh data konsentrasi radon di kota Rio de Jenerio - Brasil dalam rentang (5 sd. 200) Bq/m³ [9], di Nort India (17 sd. 51) Bq/m² [10], distrik 
Jurnal Iptek Nuklir Ganendra

Ganendra Journal of Nuclear Science and Technology

Vol. 22 No. 2, Juli 2019: 63-72

Bathinda, Punjab - India $(95 \pm 24)$ sd. $(202 \pm 90) \mathrm{Bq} / \mathrm{m}^{3}$ [11], di kota Riyadh - Arab Saudi pada rentang nilai (2 sd. 69) $\mathrm{Bq} / \mathrm{m}^{3}$ [12], di Aljouf, Saudi Arabia (3 sd. 31) Bq/m³ [13], dan di Federasi Rusia 12 sampai $207 \mathrm{~Bq} / \mathrm{m}^{3}$ [14]. Berdasarkan data tersebut maka konsentrasi radon di rumah penduduk Kalimantan Barat hampir sama dengan konsentrasi radon di kota Riyadh, Arab Saudi, serta lebih rendah dari Rio de Jenerio, Brasil.

Dari data nilai konsentrasi radon di dalam rumah maka dapat ditentukan besarnya dosis yang diterima dari kontribusi gas radon dengan menggunakan Persamaan 2. Hasil analisis dosis radiasi yang diakibatkan oleh keberadaan gas radon di dalam rumah dalam rentang nilai $(0,08 \pm 0,02) \mathrm{mSv} /$ tahun sampai dengan $(1,31 \pm 0,12)$ $\mathrm{mSv} /$ tahun. Dosis rata-rata di setiap lokasi secara lengkap disajikan pada Tabel 3.

Pada setiap grid juga dilakukan sampling bahan bangunan yang lazim digunakan masyarakat. Pada umumnya masyarakat menggunakan bahan bangunan berupa batako yang terbuat dari pasir dan semen. Sampling bahan bangunan ini dilakukan untuk mengetahui kontribusi radioaktivitas bahan bangunan terhadap besarnya konsentrasi radon di rumah penduduk. Hasil analisis konsentrasi radionuklida Ra-226, Th-232 dan K-40 dalam sampel bahan bangunan di wilayah Kalimantan Barat berturut-turut dalam rentang $(4,75 \pm 0,86) \mathrm{Bq} / \mathrm{kg}$ sampai dengan $(15,75 \pm 1,75) \mathrm{Bq} / \mathrm{kg},(2.68 \pm 0,47) \mathrm{Bq} / \mathrm{kg}$ sampai dengan $(19,64 \pm 2,16) \mathrm{Bq} / \mathrm{kg}$, dan $(15,46 \pm$ $2,04) \mathrm{Bq} / \mathrm{kg}$ sampai dengan $(217,81 \pm 21,19) \mathrm{Bq} / \mathrm{kg}$. Konsentrasi Th-232 dan K-40 terendah berada di Kec. Mempawah Hilir, Kab. Mempawah, sedangkan konsentrasi tertinggi di Kec. Sepauh, Kab. Sintang. Konsentrasi ini relatif rendah dibandingkan dengan konsentrasi rata-rata radon nasional untuk tingkat radioaktivitas lingkungan. Rendahnya konsentrasi radioaktivitas bahan bangunan juga mempengaruhi rendahnya konsentrasi radon di dalam rumah penduduk di Kalimantan Barat. Penelitian lain menyatakan bahwa pemakaian beton ringan atau hebel dapat menurunkan konsentrasi radon di dalam ruangan [15].

Tabel 4. Konsentrasi radioaktivitas bahan bangunan dari Kalimantan Barat.

\begin{tabular}{|c|c|c|c|c|}
\hline \multirow{2}{*}{ No. } & \multirow{2}{*}{ Lokasi sampling } & \multicolumn{3}{|c|}{ Konsentrasi radioaktivitas $(\mathrm{Bq} / \mathrm{kg})($ rata-rata $\pm \mathrm{SD})$} \\
\hline & & Ra-226 & Th-232 & $\mathrm{K}-40$ \\
\hline 1. & \multirow{2}{*}{$\begin{array}{l}\text { Ds. Peniti Luar, Kec. Siantan, Kab. Mempawah } \\
\text { Ds. Malikian, Kec. Mempawah Hilir, Kab. } \\
\text { Mempawah }\end{array}$} & $10,17 \pm 1,20$ & $10,55 \pm 1,27$ & $139,02 \pm 13,74$ \\
\hline 2. & & $7,26 \pm 1,11$ & $2,68 \pm 0,47$ & $15,46 \pm 2,04$ \\
\hline 3. & Ds. Sungai Rusa, Kec.Selakanu, Kab. Sambas & $7,96 \pm 1,24$ & $5,94 \pm 1,05$ & $30,12 \pm 4,09$ \\
\hline 4. & Ds. Dalem Kaum, Kec. Sambas, Kab. Sambas & $9,14 \pm 1,26$ & $8,06 \pm 1,35$ & $20,52 \pm 3,29$ \\
\hline 5. & Ds. Babane, Kec. Samalantan, Kab. Bengkayang & $4,75 \pm 0,86$ & $5,32 \pm 0,93$ & $45,96 \pm 5,50$ \\
\hline 6. & Ds. Darit, Kec. Menyuke, Kab. Landak & $12,44 \pm 1,76$ & $5,65 \pm 1,05$ & $83,95 \pm 9,44$ \\
\hline 7. & Ds. Sebungkuh, Kec. Kembayan, Kab. Sanggau & $10,13 \pm 1,19$ & $11,13 \pm 1,73$ & $145,59 \pm 15,54$ \\
\hline 8. & Ds. Binjai, Kec. Tayan Hulu, Kab. Sanggau & $11,54 \pm 1,34$ & $10,75 \pm 1,29$ & $134,14 \pm 13,28$ \\
\hline 9. & Ds. S. Kunyit, Kec. Sekadau Hilir, Kec. Sekadau & $15,75 \pm 1,75$ & $13,45 \pm 1,57$ & $205,45 \pm 20,02$ \\
\hline 10. & Ds. Gernis Jaya, Kec. Sepauh, Kab. Sintang & $10,91 \pm 1,29$ & $19,64 \pm 2,16$ & $217,81 \pm 21,19$ \\
\hline 11. & Ds. Tj. Niaga, Kec. Nanga Pinoh, Kab. Melawi & $10,55 \pm 1,56$ & $10,04 \pm 1,25$ & $91,98 \pm 9,38$ \\
\hline 12. & $\begin{array}{l}\text { Ds. Gemba Raya, Kec. Kelam Permai, Kab. } \\
\text { Sintang }\end{array}$ & $9,96 \pm 1,48$ & $13,92 \pm 2,02$ & $207,94 \pm 12,43$ \\
\hline 13. & Ds. Mubung, Kec. Hulu Gurung, Kab. Kapuas Hulu & $10,11 \pm 1,21$ & $8,93 \pm 1,46$ & $112,60 \pm 12,31$ \\
\hline 14. & Ds. Raja, Kec. Ngabang, Kab. Landak & $10,28 \pm 1,22$ & $11,57 \pm 1,39$ & $143,02 \pm 14,17$ \\
\hline 15. & Gg. Sukur-5, Jl. Veteran, Kota Pontianak & $7,26 \pm 1,11$ & $9,73 \pm 2,21$ & $128,17 \pm 12,77$ \\
\hline 16. & Komp. Pemda. Kec. Siantan Hulu, Kota Pontianak & $12,16 \pm 1,49$ & $15,54 \pm 1,82$ & $91,98 \pm 9,38$ \\
\hline
\end{tabular}

Dari hasil analisis dosis radiasi gamma secara langsung di dalam rumah menggunakan surveimeter dan dosis dari radiasi radon di dalam rumah, dapat ditentukan besarnya dosis tahunan dari radiasi alam dengan menjumlahkan keduanya. Besar dosis tahunan dari paparan radiasi gamma dan paparan gas radon di dalam rumah dalam rentang $(0,55 \pm 0,05) \mathrm{mSv} /$ tahun sampai dengan $(1,32 \pm 0,11) \mathrm{mSv} / \mathrm{tah} u n$ dan secara lengkap dapat dilihat pada Gambar 7 


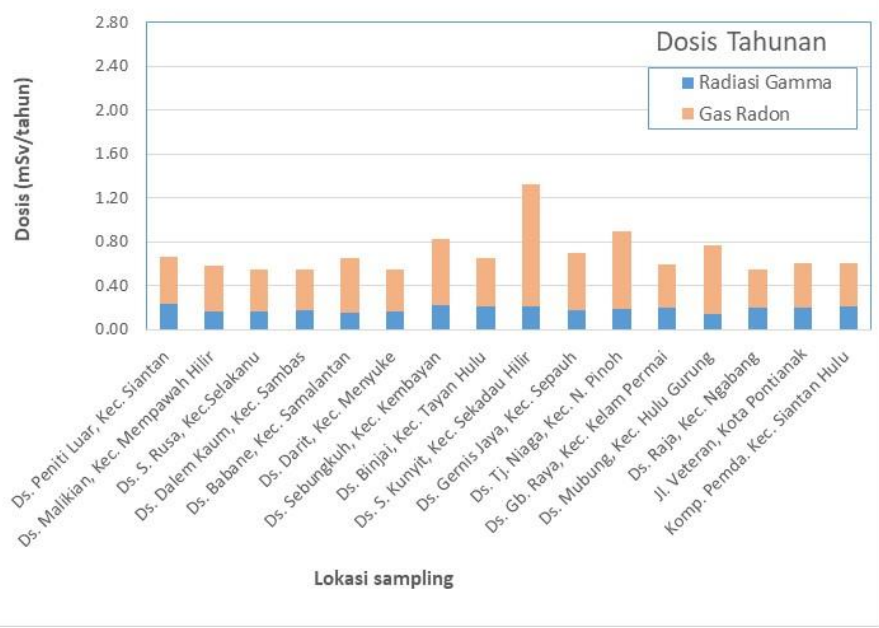

Gambar 7. Dosis tahunan dari paparan radiasi gamma dan paparan radon di rumah penduduk di Kalimantan Barat.

Dari Gambar 7 terlihat bahwa dosis radiasi gamma lingkungan di seluruh lokasi yang diukur masih di bawah $0,25 \mathrm{mSv} /$ tahun. Sedangkan untuk dosis radiasi dari gas radon relatif lebih tinggi dibandingkan dosis radiasi gamma. Hal ini kemungkinan disebabkan oleh pengaruh geologi daerah pengukuran yang mempunyai struktur tanah sedikit mengandung kapur dan terdapat bangunan dari batu bata, semen dan pasir. Hasil pengukuran tertinggi diperoleh di Desa Sungai Kunyit, Kecamatan Sekadau Hilir, Kabupaten Sekadau, dengan dosis sebesar $(1,32 \pm 0,08) \mathrm{mSv} /$ tahun yang masih di bawah nilai dosis rata-rata alam dunia sebesar 2,4 $\mathrm{mSv} /$ tahun [5]. Dari penelitian lain diperoleh data dosis radiasi di dalam rumah di Bangka Belitung dalam rentang 0,15 sampai 2,10 mSv/tahun [16]. Dari hasil tersebut maka pengaruh dominan radiasi alam di Kalimantan Barat berasal dari kondisi geologi dan sistem ventilasi serta bahan bangunan dinding rumah. Data dosis radiasi alam di dalam rumah penduduk di Kalimantan Barat yang diperoleh pada penelitian ini merupakan data dasar yang dapat dijadikan sebagai acuan dalam pengambilan kebijakan tentang radiasi alam terutama yang berasal dari gas radon di Indonesia. Data ini juga merupakan kontribusi Indonesia di dunia internasional melalui UNSCEAR, IAEA, dan WHO. Indonesia merupakan salah satu anggota UNSCEAR, PTKMR-BATAN yang mewakili Indonesia dalam kongres tahunannya di Wina - Austria berusaha selalu memberikan kontribusi data tentang dosis radiasi yang diterima masyarakat di Indonesia.

\section{KESIMPULAN}

Dari hasil analisis dosis radiasi alam dari paparan radon di rumah penduduk di Kalimantan Barat diperoleh nilai dalam rentang $(0,08 \pm 0,02) \mathrm{mSv} /$ tahun sampai dengan $(1,11 \pm 0,08) \mathrm{mSv} /$ tahun dengan rerata sebesar $(0,38 \pm 0,03) \mathrm{mSv} /$ tahun. Sedangkan untuk dosis radiasi gamma diperoleh nilai dalam rentang $(0,15 \pm 0,02)$ $\mathrm{mSv} /$ tahun sampai dengan $(0,23 \pm 0,03) \mathrm{mSv} /$ tahun. Dosis yang diterima penduduk di Kalimantan Barat sebesar $(0,55 \pm 0,05) \mathrm{mSv} /$ tahun sampai dengan $(1,32 \pm 0,11) \mathrm{mSv} /$ tahun dengan rerata sebesar $(0,69 \pm 0,20)$ $\mathrm{mSv} /$ tahun. Dapat disimpulkan bahwa dosis radiasi yang berasal dari paparan radon di dalam rumah di Kalimantan Barat masih di bawah dosis rata-rata di dunia sebesar $2.4 \mathrm{mSv} / \mathrm{tahun}$.

\section{UCAPAN TERIMA KASIH}

Ucapan terima kasih kami sampaikan kepada para pemilik rumah yang telah bersedia sebagai responden dan Bapak Dr. Susilo Widodo yang telah membimbing kami dalam penyusunan karya tulis ini. Penelitian ini dibiayai dari DIPA PTKMR-BATAN tahun 2016.

\section{DAFTAR PUSTAKA}

[1] Wahyudi, E. D. Nugraha, Kusdiana, and D. Iskandar, "Konsentrasi radon di rumah pen duduk di wilayah Kalimantan Timur," Prosiding Seminar Nasional Sains dan Teknologi Nuklir 2017, pp. 522-528, 2017.

[2] Wahyudi, D Iskandar, R Safitri, and Kusdiana, "Determination of Radon Concentrations in Dwelling in 
Aceh," J. Nat., Vol. 17, No. 2, 96-101, 2017.

[3] Wahyudi, Syarbaini, Kusdiana, "Pemetaan radioaktivitas K-40, Ra-226 dan Th-232 dalam sampel tanah dari Pulau Bangka". Prosiding Pertemuan dan Presentasi Ilmiah Fungsional Pengembangan Teknologi Nuklir IX. 154-165, 2014.

[4] P. Singh, P. Singh, S. Singh, B.K.Sahoo, B.K.Sapra, B.S.Bajwa, "A study of indoor radon, thoron and their progeny measurement in Tosham region Haryana, India," Journal of Radiation Research and Applied Sciences Vol. 8(2) 226-233, 2015.

[5] UNSCEAR, Sources and Effects of lonizing Radiation, UNSCEAR 2008 Report to the General Assembly, with Scientific Annexes, vol. I. New York: United Nations, 2010.

[6] Dinas Energi dan Sumberdaya Mineral Prov. Kalbar, "Geologi dan Air Tanah Archives."[Online].Available: https://distamben.kalbarprov.go.id/category/arsip/geologi-dan-air-tanah. [Accessed: 28-Jun-2018].

[7] ICRU Report No.88, Measurement and Reporting of Radon Exposures, Vol. 12, No. 2. Oxford University Press, 2012.

[8] I. G. A. A. Ratnawati, G. N. Sutapa, and N. N. Ratini, "The Concentration of Radon Gas in AirConditioned Indoor : Air Quality Can Increase the Potential of Lung Cancer," Int. J. Phys. Sci. Eng., Vol. 2, No. 2, 111-119, 2018.

[9] M. H. Magalhães, E. C. S. Amaral, I. Sachett, and E. R. R. Rochedo, "Radon-222 in Brazil: An outline of indoor and outdoor measurements," J. Environ. Radioact., Vol. 67, No. 2, 131-143, 2003.

[10] A. Kumar and R. P. Chauhan, "Measurement of indoor radon - thoron concentration and radon soil gas in some North Indian dwellings," Vol. 143, 155-162, 2014.

[11] S. Singh, M. Kumar, and R. K. Mahajan, "The study of indoor radon in dwellings of Bathinda district, Punjab, India and its correlation with uranium and radon exhalation rate in soil," Radiat. Meas., Vol. 39, No. 5, 535-542, 2005.

[12] F. S. Al-Saleh, "Measurements of indoor gamma radiation and radon concentrations in dwellings of Riyadh city, Saudi Arabia," Appl. Radiat. Isot., Vol. 65, No. 7, 843-848, 2007.

[13] M. D. Alenezy, "Radon Concentrations Measurement in Aljouf, Saudi Arabia Using Active Detecting Method," Nat. Sci., Vol. 6, No. July, 886-896, 2014.

[14] I. Yarmoshenko, G. Malinovsky, A. Vasilyev, and M. Zhukovsky, "Reconstruction of national distribution of indoor radon concentration in Russia using results of regional indoor radon measurement programs," J. Environ. Radioact., Vol. 150, 99-103, 2015.

[15] Syarbaini and Bunawas, "Studi Penurunan Konsentrasi Gas Radon dalam Ruangan Menggunakan Beton Ringan," J. Pemukiman, Vol. 5, No. 1, 1-6, 2010.

[16] Syarbaini, D. Iskandar, and Kusdiana, "Assessment of Radiation Dose Received by the Members of the Public in Bangka Belitung Islands Province," J. Ekol. Kesehat. Vol.14, No. 4, 318-333,2015. 